\title{
Inclusão/exclusão escolar e afetividade: repensando o fracasso escolar das crianças de classes populares
}

\section{School inclusion/exclusion and affectivity: rethinking the school failure of children from the lower social classes}

\author{
Sandra Maria Nascimento de Mattos ${ }^{1}$
}

\begin{abstract}
RESUMO
A inclusão em educação não se restringe à visão multifacetada da deficiência. Ela se constitui na dialética exclusão/inclusão, fazendo-se parte constitutiva da exclusão. Sabe-se que a antinomia exclusão/inclusão significa o direito à satisfação das necessidades básicas de aprendizagem, a eliminação das barreiras à aprendizagem e a participação de todos no sistema educativo. Entende-se que isso só ocorrerá quando direcionar-se o pensamento para o desenvolvimento de culturas, para a construção de políticas e para a orquestração de práticas inclusivas. Essas três dimensões são necessárias ao (des)envolvimento inclusivo dentro de qualquer escola que pretenda tornar-se inclusiva. O objetivo desse trabalho é mostrar a necessidade de discutir acerca da relação exclusão/inclusão, das diferenças vistas como a especificidade do ser humano e da afetividade, aspecto imprescindível para a aprendizagem. A gestão da afetividade positiva predispõe a ação e a reação em diferentes situações, fazendo com que o aluno "sinta" a aprendizagem, despertando o interesse em aprender e, assim, eliminando o fracasso escolar nas crianças de classes populares. Consequentemente, a tríade afetividade - aprendizagem - inclusão é vital para o processo educativo. Esse trabalho foi concretizado em 2009, em estudos realizados no grupo Laboratório de Pesquisa, Estudos e Apoio à Participação e à Diversidade em Educação - LaPEADE/UFRJ, e tem relação com o período das obras teóricas consultadas e o tema desenvolvido.
\end{abstract} Palavras-chave: afetividade; inclusão escolar; fracasso escolar; classe popular.

${ }^{1}$ Doutoranda em Psicologia da Educação pela Pontifícia Universidade Católica de São Paulo (PUC/SP). Participante do grupo de pesquisa: Educação, Ensino e Aprendizagem em Matemática da Universidade Federal do Rio de Janeiro (UFRJ), Brasil. E-mail: smnmattos@gmail.com. 


\begin{abstract}
The inclusion in education is not restricted to the multifaceted vision of the deficiency. It consists of the dialectic exclusion/inclusion, becoming a constituent part of the exclusion. We know that the antinomy exclusion/inclusion means the right to the satisfaction of basic learning needs, the elimination of barriers to learning and the participation of all in the educative system. It is understood that this will only occur once we direct the thought for the development of cultures, the construction of policies and the structuring practices for inclusion. These three dimensions are necessary to the inclusive development/involvement inside any school which intends to become inclusive. The objective of this work is to show the necessity to discuss the relationship exclusion/inclusion, the differences seen as specificities of the human being and the affectivity, which is an essential aspect for learning. The management of the positive affectivity predisposes the action and the reaction in different situations. It makes the pupil "feel" the learning, rousing the interest in learning, and eliminating the school failure in the children from lower social classes. Consequently, the triad affectivity-learning-inclusion is vital for the educative process. This work was conducted in 2009, through studies guided by the group LaPEADE/UFRJ, and it is related to the period of the theoretical works consulted and the developed theme.
\end{abstract}

Keywords: affectivity; school inclusion; school failure; lower social class.

\title{
Introdução
}

Em educação, a inclusão chegou para reafirmar o maior princípio já proposto internacionalmente: o princípio da educação de qualidade como um direito de todos.

(SANTOS, 2009)

Corroborando as palavras acima, entende-se que a inclusão em educação é fundamental para minimizar a exclusão no sistema educativo brasileiro. Para tanto, há a necessidade da participação coletiva e de cada um com sua singularidade, como integrantes de uma coletividade, na luta contra processos de exclusões, camuflados em ações paternalistas e assistencialistas que, tentando abolir a exclusão, acabam por perpetuá-la.

A inclusão em educação pretendida é aquela que valoriza qualquer diferença, que olha o aluno como ele é, que traz a cultura desse mesmo aluno para a sala de aula e, consequentemente, para o interior da escola, que estimula a 
criação de práticas em um agir comprometido com as maneiras de transpor o conteúdo e torná-lo crítico, reflexivo e criativo, que cria oportunidades de construir políticas de inclusão com novas formas de intervenção, garantindo a participação de todos. Não somente uma inclusão que segrega pessoas com necessidades especiais por chamar atenção para a deficiência, na tentativa de incluí-la no ensino dito "regular".

O que se entende por regular? Segundo o dicionário Aurélio, significa "1. relativo a regra. 2. Que é ou que age segundo as regras, as leis [...]" (FERREIRA, 2001, p. 592). É realmente isso que queremos para as pessoas com necessidades especiais? Então, para se estar incluída é necessário ter uma regra, agir segundo leis, quando deveria ser algo natural em qualquer ambiente, ainda mais em um ambiente educativo? O que ocorre é a tentativa de homogeneizar pessoas, quando a diversidade nos contradiz e se faz integrante de uma sociedade feita de diferenças.

Qualquer pessoa tem suas deficiências, portanto, as diferenças são trabalhadas como algo que faz parte do processo cotidiano de uma escola. Então, por que chamar atenção para as necessidades especiais? Será que é mais importante para o adulto entender assim, já que as crianças se integram rapidamente a qualquer diferença existente no outro?

\section{Reflexões acerca da exclusão}

Para falar de inclusão, torna-se necessário falar de exclusão. Exclusão que se faz pelas imagens adquiridas ao longo de um processo histórico e social do sistema educativo, que, paternalista e assistencialistamente, perpetuou episódios de fracasso escolar nas crianças de classes populares, perpassados em estigmas e estereótipos de carência cultural, de déficit de inteligência, de deficiência intelectual e das dificuldades de aprendizagem, passados pelo imaginário social e individual. "O pobre é constantemente incluído, por mediações de diferentes ordens, no nós que o exclui, gerando o sentimento de culpa individual pela exclusão" (SAWAIA, 2008, p. 9). Consequentemente, ser otimista é acreditar que a pessoa possa lutar contra a exclusão e participar ativamente do processo de ensino e aprendizagem. Ser otimista é acreditar que a pessoa possa lutar contra estar à margem da sociedade e se fazer crítico e reflexivo da mesma. Ser otimista é acreditar que a pessoa possa lutar contra um método único, que uniformiza, e construir seu conhecimento. Ser otimista é acreditar que a pessoa possa lutar 
contra uma ordem social cristalizada de paternalismo e assistencialismo e exigir dignidade e respeito.

O que significa exclusão? Segundo o dicionário Aurélio (FERREIRA, 2001, p. 304), significa “ato de excluir (-se)". Portanto, a exclusão guarda tanto o ato de excluir como o de excluir-se de um processo. Aquele que é posto ou sai de um processo. Aquele que é incompatível com o processo. Aquele que fica privado, é expulso ou retira-se de um processo. A exclusão é um processo que atinge todas as camadas sociais, porém, com maior intensidade a camada popular. Cristóvão Buarque (1993) acredita que a exclusão é um processo, no qual o ser é posto à parte, é apartado, separado do gênero humano. Assim, a exclusão é um processo cruel de apartar pessoas consideradas desqualificadas para a sociedade.

Corroborando Boneti:

[...] excluir significa expulsar do mundo dominante, significa, literalmente, pôr para fora dos parâmetros e das normas que regem as relações sociais, é não apenas marginalizar e sim desconsiderar a existência humana. Excluir significa criar e perpetuar condições sociais que tornam permanente o ato de morrer. (BONETI, 1988, p. 15).

Portanto, ser excluído ou estar em estado de exclusão é ficar à margem, sem possibilidade de participar da sociedade, das relações sociais. Segundo Martine Xiberras (1993, p. 21), "excluídos são todos aqueles que são rejeitados de nossos mercados materiais ou simbólicos, de nossos valores". Implica as imagens construídas no imaginário social como constituintes da exclusão.

Castel (1998) vê a exclusão como a desafiliação, uma ruptura de pertencimento, de vínculos societais, em que "[...] o desafiliado é aquele cuja trajetória é feita de uma série de rupturas com relação a estados de equilíbrio anteriores, mais ou menos estáveis, ou instáveis [...]" (CASTEL, 1998, p. 416). Outrossim, todo processo de exclusão é uma forma contundente de afirmar a situação de pobreza e as diversas formas de ruptura do vínculo social. Ainda em Castel (1998, p. 569), temos que "a exclusão não é uma ausência de relação social, mas um conjunto de relações sociais particulares da sociedade tomada como um todo". São essas particularidades que acirram o processo de exclusão das pessoas de classe popular, pois as tornam dependentes da condição de fragilizadas, condição de subalternização e da estigmatização da pobreza, que precisam ser beneficiadas por políticas públicas de ajuda, para minimizar as 
deficiências sociais que foram criadas ao longo de um processo de apartação social da diferença e da desigualdade.

A exclusão perpassa uma multiplicidade de trajetórias pessoais e coletivas de desvinculação, em que o próprio indivíduo se vê sem saída, aceita-se como apartado de uma sociedade que o estigmatiza como pobre e da qual precisa de favores e ajuda para poder conseguir alguma coisa. Ele precisa de apadrinhamento, de assistencialismo, de paternalismo, reforçando, ainda mais, o processo de exclusão. Essa segregação é desumana por ser simbólica. Está incutida no imaginário pessoal e social das pessoas de classe popular e modificou a identidade destes sujeitos, pois os próprios se consideram necessitados de favores para modificar sua vida socioeconômica e cultural. São mecanismos de naturalização da exclusão e de desigualdades sociais incompatíveis com a democratização da sociedade.

Para Spozati (1996), a desigualdade, que pode ser de ordem social, econômica, política, cultural e ética, para não falar na apartação social como concebida por Cristovam Buarque (1999), é incompatível com a democratização. Segundo a autora, esse processo deve ser entendido como exclusão, pois acontece a impossibilidade de partilhar, o que leva à privação, ao abandono e, consequentemente, à exclusão. De acordo com Arroyo (2000, p. 35), na "cultura social da exclusão radica a força de sua persistência, desafiando inclusive o pensamento progressista e democrático tão dominante no ideário pedagógico".

O conceito de exclusão só pode ser compreendido em uma relação dialética com seu oposto, a inclusão. Só tem sentido falar em inclusão devido à existência da exclusão. O que proporcionou o surgimento da exclusão foi o estranhamento ocorrido entre as culturas, entre a diversidade que passou a ter acesso à escola, após a obrigatoriedade.

Abordar a exclusão em sua perspectiva social requer entender os estranhamentos ocorridos no confrontamento entre as culturas ao longo dos tempos, considerando que, provavelmente, ao se depararem com a existência do outro, ambas as partes mergulharam em suas tradições, a fim de encontrarem indícios que os ajudassem a identificar os espectros com que haviam topado (GUSMÃO, 1997). O contato entre os povos se deu pela manipulação da realidade pelo grupo dominante, em um espaço de conflito e confronto, e a educação se fez como modalidade de ajustamento psicossocial. Outrossim, a exclusão se fez como produto de um sistema social cruel, que instalou-se com base em mecanismos sociopsicológicos de coação, de culpabilização individual, elaborando subjetividades determinadas por um sentimento de culpa, de frustração, de fracasso. 


\section{Reflexões acerca da inclusão}

A discussão começa na análise do termo incluir, que, segundo o dicionário Aurélio (FERREIRA, 2001, p. 380) significa "1. compreender, abranger; 2. conter em si; 3 . inserir, introduzir; 4. estar incluído ou compreendido; fazer parte; inserir-se". Inclusão é a garantia de participação de todos na sociedade, fazendo-se incluso e compreendido em um ambiente social. Significa que todas as crianças devem ser colocadas na vida social e educacional da escola sem terem sido excluídas antes pelo sistema educacional. Significa fazer algo para que elas permaneçam na escola. Incluir requer considerar peculiaridades, cruzamento de culturas, olhar a singularidade dentro da pluralidade, olhar a parte no todo e o todo na parte. Implica, ainda, considerar as crenças, mitos e valores da cada um, bem como considerar as emoções envolvidas no relacionamento.

Para Santos existe muita confusão sobre o que seja inclusão e a quem se aplica. De acordo com a autora:

Ora ela é entendida como parte de um movimento mais amplo a favor da constituição de uma escola democrática e justa, que garanta acesso e permanência dos alunos em uma escola de qualidade, ora ela é vista como restrita a discussões sobre a integração de certos grupos em especial no sistema regular de ensino, como por exemplo é o caso dos portadores de deficiência (SANTOS, 2002, p. 1).

Um sistema educativo com orientação inclusiva não se restringe aos movimentos citados acima, mas a ambos, sem distinção de qualquer espécie. A modificação do pensamento para ambos necessita privilegiar o ensino de qualidade para todos, respeitando as diferenças que porventura surjam, satisfazendo as necessidades básicas de aprendizagem, proclamadas na "Declaração Mundial sobre Educação para Todos", em Jomtien, 1990, segundo a qual satisfazer as necessidades básicas de aprendizagem

[...] compreende tanto os instrumentos essenciais para a aprendizagem (como a leitura e a escrita, a expressão oral, o cálculo, a solução de problemas), quanto os conteúdos básicos da aprendizagem (como conhecimentos, habilidades, valores e atitudes), necessários para que os seres humanos possam sobreviver, desenvolver plenamente suas 
potencialidades, viver e trabalhar com dignidade, participar plenamente do desenvolvimento, melhorar a qualidade de vida, tomar decisões fundamentadas e continuar aprendendo. (DECLARAÇÃO MUNDIAL SOBRE EDUCAÇÃO PARA TODOS, 1990)

Consequentemente, a inclusão em educação assegura o respeito ao desenvolvimento humano em seus diversos aspectos (cultural, social, emocional, linguístico e espiritual) e a solidariedade, assegurando crenças, costumes e valores que garantam dignidade e a construção da identidade.

Segundo Stainback e Stainback:

Uma escola inclusiva [...] é aquela que educa todos os alunos em salas de aulas regulares. Educar todos os alunos em salas de aulas regulares significa que todo aluno recebe educação e frequenta aulas regulares. Também significa que todos os alunos recebem oportunidades educacionais adequadas, que são desafiadoras, porém ajustadas às suas habilidades e necessidades, recebem todo o apoio e ajuda de que eles e seus professores possam, da mesma forma, necessitar para alcançar sucesso nas principais atividades. [...] Ela é um lugar do qual todos fazem parte, em que todos são aceitos, onde todos ajudam e são ajudados por seus colegas e por outros membros da comunidade escolar, para que suas necessidades educacionais sejam satisfeitas (STAINBACK; STAINBACK, 1999, p. 11).

Recai-se novamente na "Declaração Mundial de Educação para Todos" sobre a universalização de acesso à educação com equidade, em que qualquer pessoa tem oportunidade de uma aprendizagem de qualidade, sem sofrer qualquer tipo de discriminação, independente da diversidade que possa ocorrer no sistema educativo. Assim, essa aprendizagem de qualidade explora abordagens significativas, isto é, que tenham fundamentos na cultura do aluno; ativas e criativas, em que este terá condições de explorar plenamente suas potencialidades.

A quem realmente tenta-se incluir? A qualquer pessoa sem distinção, entretanto, o foco são as crianças de classes populares com alto índice de fracasso escolar, que foram estigmatizadas e estereotipadas nos contextos educacionais brasileiros, ao longo do processo educativo. Aquelas pessoas que, por sofrerem constantemente atos discriminatórios, acabam por se culpar pelo desempenho alcançado e desconfiar de si mesmas, colocando-se como aquelas que têm dificuldades e problemas de aprendizagem. 
O que é estar incluído? Segundo Spozati (2000), o não fracasso significa um indicador de inclusão. Alfabetizar-se, qualidade de escolarização, escola próxima à residência, assegurar o cumprimento dos programas pedagógicos ao longo de escolarização, ter acesso à escola e ter aulas, ajustar os conteúdos pedagógicos à realidade da criança de classes populares, todos esses aspectos são indicadores de inclusão. Consequentemente, estar incluído demanda a superação da exclusão escolar que "[...] muito mais do que mero direito a vaga e permanência, demanda a superação dos valores que segregam e banem o indivíduo no cotidiano de uma experiência em que jamais consegue superar os limites do intolerável, do fracasso eminente" (SENNA, 2008, p. 202).

No Brasil, a garantia do exercício da cidadania passa pela desnaturalização das formas de discriminação e das formas de favores, como um direito do pobre, que, não tendo acesso às condições necessárias a sua sobrevivência, "ganha" ajuda, o que estigmatiza mais ainda a pobreza. Esses favores são traduzidos como a cultura da tutela. São essas formas de minimizar a disparidade gritante entre as classes que reforçam cada vez mais a exclusão.

Nessa mesma perspectiva, a inclusão acaba por tornar-se indispensável como um processo social contemporâneo. Porém, a educação inclusiva busca a minimização de qualquer tipo de exclusão, abrindo caminho para que a pessoa possa fazer suas escolhas e decidir seus destinos, sem entendê-los como pessoas que precisam de ajuda, mas como pessoas que têm potencial para, por elas próprias, resolverem suas necessidades e desenvolverem suas potencialidades.

\section{A afetividade como fator de inclusão}

Como mestre, só posso então lhe dizer uma coisa: conte-me seus sonhos, para que sonhemos juntos!

(RUBEM ALVES, 2007)

Como diz Rubem Alves (2007), é preciso sonhar, mas sonhar os sonhos possíveis, como afirmava Paulo Freire (1982). Sonhos que se tornarão realidade quando há o empenho em resolver o problema. Sonhos que poderão modificar o imaginário social, passado ao longo de várias décadas, pois se tenta sonhar o sonho possível e transformar o mito do fracasso escolar em não fracasso, em sucesso escolar das crianças de classes populares. No entanto, precisam-se sonhar juntos e imaginar um sistema de ensino de qualidade para todos em que sejam satisfeitas as necessidades básicas de aprendizagem. Nesse sistema de ensino não haverá necessidade de inclusão, porque não haverá exclusões. 
Segundo Sawaia (2008, p. 98), "ao falar de exclusão, fala-se de desejo, temporalidade e de afetividade, ao mesmo tempo que de poder, de economia e de direitos sociais". Consequentemente, encontra-se a afetividade $^{2}$ como um recurso que legitima as reflexões sobre as desigualdades sociais, a diversidade, a discriminação e preocupação com a classe popular no que tange ao sofrimento do pobre frente à falta das condições essenciais básicas de sobrevivência, dentre elas a educação.

Vygotsky (2004, p. 136) afirma que se deve entender "a emoção como reação nos momentos críticos e catastróficos do comportamento" e que "a reação emocional enquanto reação secundária é um poderoso organizador do comportamento" (2004, p. 137). Assim, se faz-se algo com alegria tem-se êxito e se faz-se algo com repulsa procura-se interrompê-lo a qualquer custo. Ainda segundo Vygotsty (1998, p. 259), a emoção não pode desempenhar o papel passivo do fenômeno, ela se manifesta em reações e ações que geram prejuízos ao aprendizado da criança. Sawaia, citando Vigotsky (2008, p. 103), afirma que ele:

Reflete que a emoção e o sentimento não são entidades absolutas ou lógicas do nosso psiquismo, mas significados radicados no viver cotidiano, que afetam nosso sistema psicológico pela mediação das intersubjetividades. Os processos psicológicos, as relações exteriores e o organismo biológico se conectam através das mediações semióticas, configurando motivos, que são estados portadores de um valor emocional estável, desencadeadores da ação e do pensamento.

Comprovando que as inter-relações sociais interferem nas ações, reações e decisões configuradas pelas mediações estabelecidas no processo vivido cotidianamente.

Na teoria de Wallon $(1995,2007)$, a dimensão afetiva é enfatizada de maneira significativa para a construção da pessoa e do conhecimento. A afetividade

\footnotetext{
${ }^{2}$ A afetividade é entendida como qualidade de ser afetivo; aquele que tem afeto por algo ou alguém. Afeto - do latim affectus, designa o conjunto de atos ou de atitudes como a bondade, a benevolência, a inclinação, a devoção, a proteção, o apego, a gratidão, a ternura, etc, que no seu todo podem ser caracterizados como a situação em que a pessoa "preocupa-se com" ou "cuida de" outra pessoa em que esta responde, positivamente, aos cuidados ou à preocupação de que foi objeto. (ABBAGNANO, 2000, p. 21). Bem como, corroborando com Sawaia (2008, p. 98), entendemos ainda a afetividade como: "a tonalidade e a cor emocional que impregna a existência do ser humano e se apresenta como: 1) sentimento: reações moderadas de prazer e desprazer, que não se refere a objetos específicos; 2) emoção, fenômeno afetivo intenso, breve e centrado em fenômenos que interrompem o fluxo normal da conduta".
} 
e a inteligência são inseparáveis na evolução psíquica. Os aspectos cognitivo e afetivo ocorrem entre oposição e complementaridade, em que, dependendo da atividade, há a preponderância do afetivo ou do cognitivo, o que não exclui um em relação ao outro, porém ocorrem alternâncias em que um mergulha para que o outro possa emergir.

Freire (2005, p. 29) nos fala que "não há educação sem amor" e "quem não ama não compreende o próximo", o que justifica a busca da inclusão pela afetividade no cotidiano escolar. Pode-se, ainda, afirmar que "sem vínculo, o amor não cresce, [...]. Não creia em manuais mágicos na educação. Creia na sensibilidade." (CURY, 2001, p. 23). Portanto, a afetividade precisa estar presente em todos os momentos na sala de aula para efetivar a inclusão em educação.

Em Mattos (2008a, p. 177), tem-se que "a afetividade pode traduzir-se por afeição a alguém, de simpatia, de amizade que faz um relacionamento ter cumplicidade. É a sensação psíquica de bem-estar com o outro, com a propensão de ser impressionado pelo outro". Chama-se essa simpatia de empatia ${ }^{3}$, que é fonte fundamental para o ensino e a aprendizagem, pois a pessoa é colocada no lugar do outro e entendemos seus sentimentos.

Para Mattos (2008b, p. 55), "a afetividade é algo extremamente complicado de gerir. Ela medeia entre o bem-estar e o mal-estar". Toma-se a afetividade positiva por ser aquela que permite a escuta empática ${ }^{4}$, o que significa reformular as falas do outro no intuito de compreendê-lo; devolvendo-lhe aquilo que concerne essencialmente à sua afetividade, em um confrontamento consigo mesmo, forçando-o a rever seu caminho para chegar à solução de um problema. É um refletir sobre si mesmo. É o autêntico "conheça a ti mesmo" de Sócrates.

A afetividade é um caminho para incluir qualquer educando no ambiente escolar. É a mediadora entre a aprendizagem e os relacionamentos desenvolvidos em sala de aula, na busca da inclusão de qualquer educando na escola. Entende-se a diferença como a especificidade de cada um, em seus múltiplos e complexos comportamentos. Entende-se, ainda, a diferença como o vivido de cada um, em sua realidade social e cultural. Entende-se, mais ainda, que a permanência do educando na escola depende da aceitação, da motivação e da autoconfiança que ele percebe quando entra no ambiente escolar. Esses fatores e tantos outros podem facilitar a permanência e a aprendizagem. O domínio

${ }^{3}$ Empatia é uma resposta afetiva apropriada à situação. Pode ser cognitiva, que é a capacidade de compreender a perspectiva de outra pessoa. E pode ser afetiva, que é a capacidade de experimentar reações emocionais por meio da observação realizada sobre a experiência de outra pessoa.

${ }^{4}$ Escuta empática, segundo Chabot e Chabot (2008,p. 170-172), é a reformulação, que é um dos modos mais significativos de ouvir alguém, em que o educando sente-se ouvido e compreendido, impulsionado a dar mais um passo para completar o que acabou de executar. 
afetivo possibilita o desenvolvimento das relações afetivas, permitindo que acontecimentos exteriores - quando positivos - dirijam o comportamento dos educandos, para que assumam o compromisso com a sua aprendizagem.

\section{A afetividade positiva na modificação do fracasso escolar em inclusão}

As crianças de classes populares são aquelas que ficam à margem do sistema social e educacional. Que precisam, primeiro, de inclusão social e econômica, para só então ter inclusão escolar. Spozati (2000, p. 23) fala de "não fracasso como forma de inclusão social", inclusão social onde pais precisam ser alfabetizados, crianças precisam de registro de nascimento, saúde pré e pós-natal, alimentação saudável, condições básicas para se desenvolver, habitação, lazer e, acima de tudo, ser reconhecidas como cidadãos brasileiros.

A criança de classe popular tem seu mundo circunscrito às atividades desenvolvidas na escola. E quanto mais pobre, mais a sala de aula se torna seu mundo. Entende-se como Spozati que

A relação entre a cultura da escola e a cultura local é fundamental para fazer da escola um espaço de articulação de mentes e não só de corpos (dos alunos), das emoções e desejos das crianças. Essa valorização é que permite uma nova via de inclusão e cidadania. (SPOZATI, 2000, p. 29).

A gestão da afetividade positiva proporciona prazer e alegria, bem como predispõe a reagir, em diferentes situações, adequadamente. $\mathrm{O}$ educador pode dar apoio ao educando, ajudando-o a superar os bloqueios emocionais com relação a uma determinada disciplina. Outrossim, o educador possibilita a identificação e a gestão das emoções nocivas à aprendizagem.

De acordo com Chabot e Chabot (2008, p. 131):

Um dos papéis do educador emocionalmente inteligente consiste em estimular as competências emocionais de seus alunos. [...] O professor deve, pois, utilizar meios que permitam ao aluno sentir as coisas que aprende. Deverá, então encontrar o modo de estimular seu lóbulo 
pré-frontal esquerdo, a fim de otimizar seu bem-estar emocional. Poderá, consequentemente, solicitar e estimular todas as competências emocionais do aluno.

O bem-estar emocional possibilita ao educando estabelecer a ligação entre o que é ensinado e os sentimentos que favorecem o "sentir" o aprender. A atividade afetiva intensa faz com que o educando se volte para si e consiga desenvolver sua inteligência emocional, o que possibilita emergir a atenção, a motivação, o engajamento e, acima de tudo, o interesse em aprender.

O educador necessita tornar-se um educador empático, pois poderá perceber os sinais dados pelo educando e reverter os aspectos negativos em positivos e efetivamente ensinar. Assim, concorda-se com Goleman (apud CHABOT; CHABOT, 2008, p. 141):

Os indivíduos empáticos sabem ouvir os inúmeros sinais emocionais e isto faz com que sintam as emoções não explícitas de uma pessoa ou de um grupo. São capazes de ouvir com atenção e de compreender a perspectiva do outro. Um indivíduo dotado de empatia não terá dificuldades para entender-se com pessoas de meios diversos e de outras culturas.

Dessa forma, o educador torna possível a afetividade positiva, compreendendo a diversidade contida em seus alunos e favorecendo o "cruzamento de culturas" (PÉREZ GÓMEZ, 2000), tão necessário à aproximação, à permanência e ao interesse em aprender em um ambiente escolar. Esse cruzamento provoca e evoca tensões, contrastando significados que, relegados, podem levar ao abandono escolar. O educando torna-se agressivo, violento, apático ou medroso, por não compreender os significados não contextualizados em sua cultura de origem.

Corroborando Petrovsky (apud LEITE, 2005, p. 77), entende-se que "as emoções humanas são transformadas pelas condições sociais da existência do homem e se manifestam, executando certos casos patológicos, em forma socialmente condicionada". Portanto, existem mediações socialmente condicionadas que interferem no desenvolvimento afetivo da criança de classe popular. Ainda em Leite (2005) tem-se que "o surgimento das emoções - entendidas como um estado individual em movimento - estaria determinado em maior escala pelas variações situacionais do meio e, em menor escala, por necessidades internas". O que corrobora a hipótese que o meio social e cultural, passado pelo imaginário 
social, traz consequências desastrosas para as crianças da classe popular, com índice de fracasso escolar.

De acordo com Moysés e Collares (1993, p. 13), “o cotidiano escolar é permeado de preconceitos, juízos prévios sobre os alunos e suas famílias, que independem e não são abalados por qualquer evidência empírica que os refute racionalmente". Esse cotidiano é vivenciado em sala de aula e no ambiente escolar, prejudicando a aprendizagem do educando. Um educador que venha imbuído pelo espírito de que tal educando é "assim ou assado" já o vê com outros olhos. Essas opiniões, apreciações prévias passadas entre os educadores, distorcem a realidade e podem provocar a exclusão do aluno do sistema educativo. São preconceitos impregnados no imaginário coletivo e pessoal escolar. De acordo com Mattos (2007, p. 33), ter preconceito "significa formar no espírito uma ideia que se imagina como sendo verdadeira. Significa formar um conceito ou uma opinião antes de ter os conhecimentos adequados" sobre o educando.

De acordo com Bossa (2000, p. 18), sabe-se "que o sentido da aprendizagem é único e particular na vida de cada um, e que inúmeros são os fatores afetivos que podem impedir o investimento energético necessário às aquisições escolares”. Sabe-se, também, que vários fatores podem atrapalhar a vida escolar. Porém, o relacionamento com o educador é um fator que pode trazer, ou não, consequências desastrosas. O educador precisa utilizar a criatividade como forma de "seduzir" o educando a aprender. Seduzir, no sentido utilizado por Codo e Gazzotti (2002, p. 58), como "trazer para o seu lado", produzindo a cumplicidade que gera aprendizagem significativa. "É mediante o estabelecimento de vínculos afetivos que ocorre o processo de ensino-aprendizagem".

Há uma patologização do fracasso escolar com referência às crianças da classe popular. Normas escolares pioram essa patologização e fortalecem os estereótipos de déficit e carência cultural. Para Perrenoud (2001, p. 16):

Parecia normal que a escola agrupasse crianças dotadas e outras não, crianças nascidas para estudar e outras nascidas para o trabalho aos doze anos. E mais normal ainda que o sucesso estivesse estreitamente vinculado à condição social de origem: era a ordem das coisas. A exigência de igualdade não estava ausente, mas a escolarização e a alfabetização mínima de todos eram suficientes para satisfazê-la.

Portanto, a normalização da escola impulsiona ao fracasso escolar, fazendo com que a criança da classe popular acredite que está recebendo o máximo que a escola pode lhe oferecer. É importante para a escola a identificação de ações 
culturais de inclusão, a construção de práticas de inclusão e a formulação de políticas inclusivas que permitam o acesso de todos à educação de qualidade.

\section{(In)Concluindo...}

Entende-se que o ser humano se faz como um ser afetivo e cognitivo e que o domínio afetivo se completa com o domínio cognitivo, ocorrendo em um misto de oposição e complementaridade. Mesclando altos e baixos, em que o afetivo sobressai ao cognitivo ou vice-versa e um não exclui o outro, mas fortalece. Sabe-se que as crianças de classes populares se alfabetizam do mesmo jeito que as crianças de outras classes. Então, por que ocorre essa discrepância? Pela simples razão de existir uma classe social dominando a outra, por ser entendida como hegemônica.

Acredita-se que o imaginário social e coletivo pode ser modificado com o estímulo à autoestima, à autoconfiança, à empatia, facilitado pela busca do sistema emocional dessas crianças, via afetividade, para reestruturar os mecanismos de organização do pensamento, de forma que elas consigam aprender e permanecer no ambiente escolar.

É importante a relação com o outro para o desenvolvimento cognitivo e afetivo, pois o sujeito não se encontra isolado do grupo com o qual convive e, portanto, sente necessidade de ser aceito pelo mesmo. Bustos $(1979$, p. 16) afirma que "sem vínculos o homem não existe", provando que as escolhas manifestam um determinado padrão frente a um contexto, em um determinado tempo, em um determinado espaço, com uma história que se faz nas inter-relações do sujeito com o outro e com seu grupo de convívio. Ainda segundo Bustos $(1979$, p. 16), afirma-se que "o homem que observa o faz basicamente a partir de uma escala de valores que responda ao meio social no qual ele vive". Consequentemente, esses valores trazem a carga do imaginário social e coletivo, bem como o imaginário pessoal, todos passados de geração a geração através da família e do grupo social que nos contextualiza.

Concordando com Ricoeur (apud MARTINET, 1981, p. 95), afirma-se que "as emoções têm um poder de sacudir a ação, de emocionar o ser, poder que não consiste a princípio em o pôr fora de si, mas em tirar da inércia por uma espontaneidade sempre perigosa para o domínio de si; se a vontade deve sempre estar acima dessa espontaneidade, é no entanto através desta que ela move o corpo." Entende-se, então, que existe um caminho direcionado à modificação do imaginário social e pessoal, rumo ao sucesso escolar, que passa 
pela inclusão escolar de todos indistintamente, que passa pela qualidade de aprendizagem, que passa pela inclusão social sem distinção de raça, crença, etnia, sexo e classe social.

Entende-se, ainda, que é por meio do outro que a criança da classe popular enxerga o mundo e concebe seus valores. É por meio do outro que a criança da classe popular poderá ser compreendida e fazer-se compreender. A criança age sobre o outro e adquire suas convicções, valores e crenças, portanto, é chegada a hora de modificar o imaginário do fracasso escolar com o auxílio da afetividade, em uma tentativa de modificar os modelos organizadores do pensamento. É chegada a hora de combater a banalização do mal (ARENDT, 1999) do outro. De introduzir a afetividade para enfrentar a exclusão social e, por consequência, escolar. De colocar a felicidade - entendida como centrar-se na humanização - como critério para definir maneiras de inclusão, vista como o cuidado com o outro pela sociedade e pela escola, sem negar sua particularidade em meio à pluralidade de identidades existentes.

\section{REFERÊNCIAS}

ABBAGNANO, Nicola. Dicionário de Filosofia. São Paulo: Martins Fontes, 2000.

ALVES, Rubem. A alegria de ensinar. 11. ed. São Paulo: Papirus, 2007.

ARENDT, Hannah. Eichmann em Jerusalém: um relato sobre a banalidade do mal. São Paulo: Companhia das Letras, 1999.

ARROYO, Miguel. Fracasso-sucesso: um pesadelo que perturba nossos sonhos. Em Aberto, Brasília, v. 17, n. 7, p. 33-40, Brasília, jan. 2000.

BONETI, L. W. Estado e exclusão social hoje. In: ZARTH, P. (Org.). Os caminhos da exclusão social. Ijuí: Unijuí, 1988.

BOSSA, Nádia Aparecida: Dificuldades de aprendizagem: O que são? Como tratá-las? Porto Alegre: ArtMed, 2000.

BUARQUE, Cristovam. A revolução das prioridades. Instituto de Estudos Econômicos (INESC), 1993.

. O que é apartação: o apartheid social no Brasil. São Paulo: Brasiliense, 1999. Disponível em: <http://www.webartigos.com/articles/31904/1/Invisibilidade-social-a-outra-face-do-preconceito/pagina1.html\#ixzz11t2HMR00>. Acesso em: 22/05/2009.

BUSTOS, Dalmiro Manuel. O teste sociométrico. São Paulo: Brasiliense; 1979. 
CASTEL, Robert. As metamorfoses da questão social: uma crônica do salário. Petrópolis: Vozes, 1998.

CHABOT, Daniel; CHABOT, Michel: Pedagogia emocional: sentir para aprender. Trad. de Diego Ambrosini e Juliana Montoia de Lima. São Paulo: Sá, 2008.

CODO, Wanderley (Coord.); GAZZOTTI, Andréa Alexandra. Educação, carinho e trabalho. 3. ed. Petrópolis: Vozes, 2002.

CURY, Augusto Jorge. Treinando a emoção para ser feliz. São Paulo: Academia de Inteligência, 2001.

FERREIRA, Aurélio Buarque de Holanda. Novo Dicionário da Língua Portuguesa. 4. ed. Rio de Janeiro: Nova Fronteira, 2001.

FREIRE, Paulo. Educação: o sonho possível. In: BRANDÃO, Carlos Rodrigues (Org.). O educador: vida e morte. Rio de Janeiro: Graal, 1982.

. Educação e mudança. v. 1. 28. ed. Rio de Janeiro: Paz e Terra, 2005. (Coleção Educação e Comunicação)

GUSMÃO, Neusa Maria Mendes de. Antropologia e educação: origens de um diálogo. Cad. CEDES, Campinas, v. 18, n. 43, p. 8-25, dez. 1997.

LEITE, Ivanise. Emoções, sentimentos e afetos: uma reflexão sócio-histórica. 2. ed. São Paulo: Junqueira \& Marin Editores, 2005.

MARTINET, M. Teoria das emoções: introdução à obra de Henri Wallon. Trad. de J. Seabra-Dinis. Lisboa: Moraes Editores, 1981.

MATTOS, Sandra Maria Nascimento de. O educador oculto: em busca do imaginário pedagógico na prática docente. Dissertação (Mestrado) - UCP. Petrópolis, 2007.

. Avaliar: um diálogo da afetividade com a rede de relações desenvolvidas no cotidiano escolar. Revista de Educação PUC-Campinas, Campinas, n. 25, p. 173-181, nov. 2008a.

. A afetividade como fator de inclusão. Revista Teias online, Rio de Janeiro, ano 9, n. 18. julho/dez. 2008b. p. 50-59. Disponível em: $<$ http://www.periodicos.proped.pro. br/index.php?journal=revistateias $>$. Acesso em: 22/05/2009.

MOYSÉS, M.; COLLARES, C. Alfabetização: passado, presente, futuro. Revista Ideias, São Paulo, n. 19, pp. 9-25, 1993.

PÉREZ-GÓMEZ, A. I. Ensino para a compreensão. In: GIMENO SACRISTÁN, J.; PÉREZ-GÓMEZ, A. I. (Orgs.). Compreender e transformar o ensino. Porto Alegre: Artmed, 2000.

PERRENOUD, Philippe. A pedagogia na escola das diferenças. Porto Alegre: Artmed, 2001. 
SANTOS, Mônica Pereira dos. Ressignificando a escola na proposta inclusiva, 2002. Disponível em: <http://www.educacaoonline.pro.br/art_ressignificando-a-escola-na-proposta-inclusiva.asp $>$. Acesso em: 15/06/2009.

. Prefácio. In: ; PAULINO, Marcos Moreira (Orgs.). Inclusão em Educação: culturas, políticas e práticas. São Paulo: Cortez, 2006.

. Inclusão. In: ; FONSECA, Michele Pereira de Souza da; MELO, Sandra Cordeiro (Orgs.). Inclusão em educação: diferentes interfaces. Curitiba: CRV, 2009.

; PAULINO, Marcos Moreira. Inclusão em educação: uma visão geral. In: ; (Orgs.). Inclusão em Educação: culturas, políticas e práticas. São Paulo: Cortez, 2006.

SAWAIA, Bader. Introdução: exclusão ou inclusão perversa? In: (Org.). As artimanhas da exclusão: análise psicossocial e ética da desigualdade social. 8. ed. Petrópolis: Vozes, 2008.

SENNA, Luiz Antonio Gomes. Formação docente e educação inclusiva. Cadernos de Pesquisa, v. 38, n. 133, p. 195-219, jan./abr. 2008.

SPOZATI, Aldaíza (Coord.). Mapa da exclusão/inclusão social da cidade de São Paulo. São Paulo: EDUC, 1996. jan. 2000.

Exclusão social e fracasso escolar. Em Aberto, Brasília, v. 17, n. 71, p. 21-32,

STAINBACK, Susan; STAINBACK, William. Inclusão: um guia para educadores. Trad. de Magda França Lopes. Porto Alegre: Artmed, 1999.

UNESCO. Declaração Mundial sobre Educação para Todos: necessidades básicas de aprendizagem. Jomtien, 1990. Disponível em: http://unesdoc.unesco.org/ images/0008/000862/086291por.pdf. Acesso em 22/05/2009.

VYGOTSKY, L. S. Théorie des émotions: étude historico-psychologique. Trad. de Nicolas Zavialoff e Christian Saunier. Paris: L'Harmattan, 1998.

2004.

. Psicologia pedagógica. Trad. Paulo Bezerra. 2. ed. São Paulo: Martins Fontes,

XIBERRAS, Martine. Les theories de l'exclusion. Paris: Meridiens-Klincksieck, 1993.

WALLON, Henry. As origens do caráter na criança. São Paulo: Nova Alexandria, 1995. . A evolução psicológica da criança. São Paulo: Martins Fontes, 2007.

Texto recebido em 18 de outubro de 2009.

Texto aprovado em 25 de maio de 2011. 